\title{
Periapical Healing Following Bypass of a Separated Instrument in a Mandibular Molar - A Case Report
}

\author{
Shahab Javanmardi ${ }^{1}$, Gurdeep Singh ${ }^{2 *}$ and Talal Al-Nahlawi ${ }^{3}$ \\ ${ }^{1}$ Specialist Endodontist at Mohammad Orthodontic Center, Muscat, Oman \\ ${ }^{2}$ Senior Lecturer Adult Restorative Dentistry at Oman Dental College, Muscat, \\ Oman \\ ${ }^{3}$ Professor of Endodontics and Operative Dentistry at Syrian Private University, \\ Syria \\ *Corresponding Author: Gurdeep Singh, Senior Lecturer Adult Restorative \\ Dentistry at Oman Dental College, Muscat, Oman.
}

Received: August 16, 2021

Published: August 31, 2021

(C) All rights are reserved by Gurdeep Singh., et al.

\begin{abstract}
When a file fractures during root canal treatment, there are several treatment options available for the clinician. The definitive management should be based on a thorough knowledge of the success rates of each treatment option, balanced against potential risks of removal or file retention, with the availability of needed equipment and skills if the treating dentist. This paper describes a case of separated instrument which was treated by bypassing the separated fragment with one year follow up of the root canal treatment.
\end{abstract}

Keywords: Periapical Healing; Separated Instrument; Mandibular Molar

\section{Introduction}

Separation of Endodontic instruments within root canal is one of many procedural errors that might happen during endodontic therapy. In which it can hinder the root canal procedure and the outcome $[1,2]$.

Nickel-titanium (NiTi) instruments have become extremely popular in endodontic practice. NiTi instruments are more flexible than stainless steel instruments and can revert to their original shape (memory) after use. With advent of superelastic NiTi instruments, the efficiency of endodontic cleaning and shaping has been greatly improved, especially in the curved canals [3-5]. These in- struments can minimize the procedural errors, such as ledge and transportation, and create more rounded/centered canal preparation $[4,6,7]$. However, there is limit to the amount of flexure an instrument can withstand. When this limit is reached or exceeded, the instrument will distort or fracture $[8,9]$.

The clinical decision should be based on thorough knowledge of success rate of each; treatment options, constraints of the root canal accommodating the fragment, the stage of root canal instrumentation at which the instrument separated, the expertise of the clinician, armamentaria available, possible associated complications, the strategic importance of the tooth involved, and the presence/or absence of periapical pathosis [10]. 
In the present case report, it has been illustrated that management of separated instrument in the root canal of mandibular second molar by bypassing may be a more conservative approach along with a one year follow up.

\section{Case Description}

A 30-year-old male patient intact physically with no general diseases was referred to our speciality dental office by a general dental practitioner, following separation of an instrument in the mesial canal of the mandibular right second molar. Patient was complaining of pain which was localized to tooth \#47. After clinical and radiographic examination, extensive carious lesion was noticed, there was pain on percussion, and radiographically; The canals had been previously poorly root filled and a preapical lesion was evident involving the mesial roots. The case was diagnosed as symptomatic apical periodontitis in a previously root canal initiated tooth [11]. In addition to a finding of a fractured instrument which was positioned at the apical third beyond the curvature in the mesio-lingual canal (Figure 1).

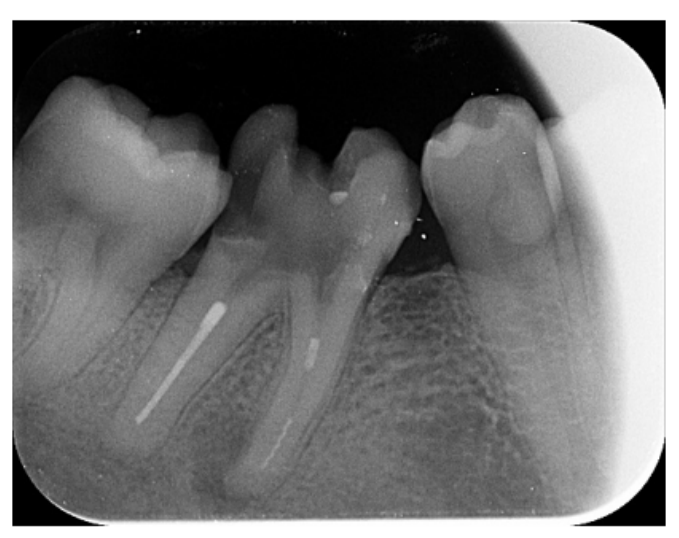

Figure 1: Pre-Operative of tooth 47.

The treatment of this was planned as non-surgical root canal retreatment of tooth \#47 and the options was explained in detail to the patient, detailed consent form was signed, and it was agreed to try to remove the separated file and if it did not work then change the plan to bypassing the separated file. In the first visit, LA (Octocaine $^{\circledR} 100$, Lidocaine $\mathrm{HCl} 2 \%$ and Epinephrine 1:10,000) was ad- ministered, and rubber dam isolation was applied. The tooth was excavated from all the carious lesion, pre-endobuild up with deep margibal elevation was achieved with composite resin. The access was prepared, and three canals were located, mesio-buccal, mesiolingual, and distal canal. The previous root canal filling material (gp) were removed by using PROTAPER Universal Retreatment Kit (Dentsply Sirona ${ }^{\circledR}$ ) and the canals were instrumented with PROTAPER GOLD rotary file (Dentsply Sirona ${ }^{\circledR}$ ). Removing the separated instrument was attempt by using brading tech, but however, its position beyond the curvature in the mesio-lingual canal with inavailablity of dental microscope at the dental office made the removal option of separated file contraindicated. Instead, it was decided to bypass the separated instrument in the mesio-lingual canal inorder to better debrid and disinfect the mesio-lingual canal. Bypassing separated instrument was achived by using $\mathrm{K}$ files (SybronEndo) sequence: 0.6, 0.8, 10, 15 and 20 (Figure 2 and 3). PROTAPER GOLD (Dentsply Sirona ${ }^{\circledR}$ ) was used then to instrument the canal till size F2. Sodium hypochlorite 3\% $\left(\right.$ Hyposol $\left.^{\circledR}\right)$ was used with endo safety needle gage 27 for the irrigation. The final irrigation was done with sterile saline, then canals were dried with paper point and a non-setting calcium hydroxide (TPaste, Nexobio ${ }^{\circledR}$ ) was placed in the canals as intercanal medicament, and the tooth was closed with temporary filling $\left(\right.$ MetaBiomed $\left.^{\circledR}\right)$. The patient was recalled after one week.

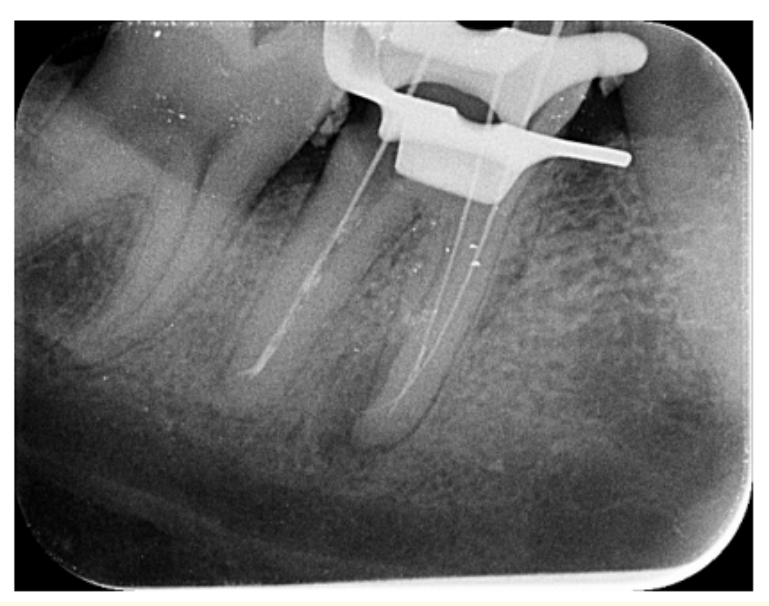

Figure 2: Removing the old filling material and filling material. Bypassing of the separated instrument. 


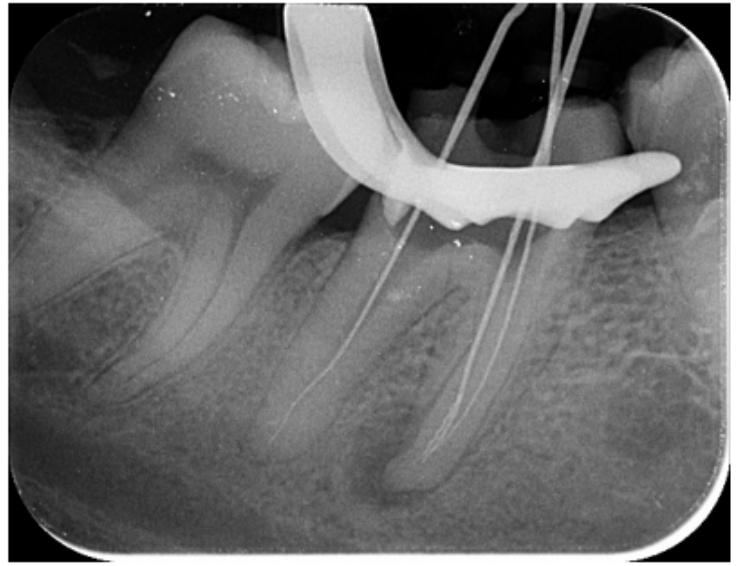

Figure 3: By passing the separated instrument.

In the second visit, the tooth was completely asymptomatic, no pain on percussion. The tooth was re-accessed under LA and after placing rubber dam. The intercanal medicament was irrigated thoroughly with sterile saline followed irrigation with sodium hypochlorite 3\% $\left(\right.$ Hyposol $^{\circledR}$ ) followed by sterile saline. Final irrigation was done with $17 \%$ EDTA (Cerkamed ${ }^{\circledR}$ ) to remove the smear layer and final irrigation was with sterile saline. The canals were dried and were ready for obturation. Sealer AH Plus (Dentsply Sirona) which was used to coat the canals. The obturation was done with continuous wave warm vertical obturation using FAST PACK and FAST FILL (EIGHTEETH ${ }^{\circledR}$ ). This was followed by restoring the tooth with composite resin (Figure 4). A Zirconia crown was placed on the tooth after one week of its treatment. The patient was only able to attend for review after 1 year; the follow-up radiograph showed healing of the pre-apical lesion (Figure 5 and 6).

\section{Discussion}

When a root canal instrument fractures and remain inside canal, potentially abstracting further cleaning, shaping and filling. Instrument separation may occur with hand or enginedriven instruments either due to cyclic fatigue, and/or torsional failure. Cyclic fatigue occurs when an instrument is rotated in a curved canal whilst undergoing multiple tensile and com-

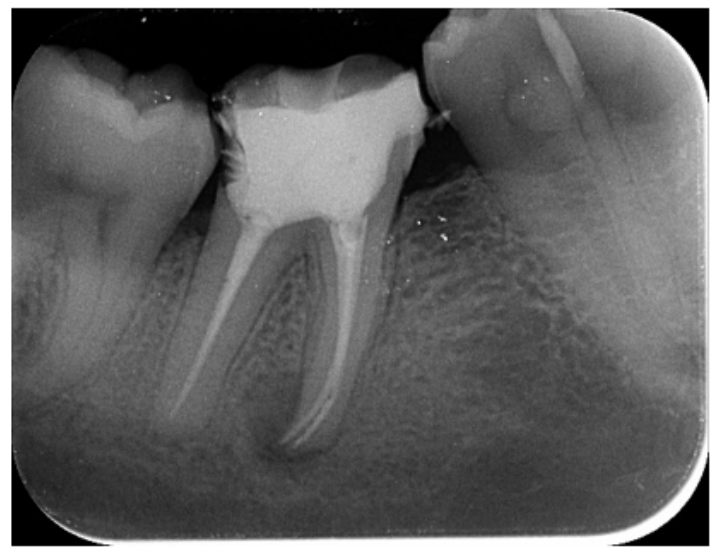

Figure 4: Obturation and restoration of the tooth.

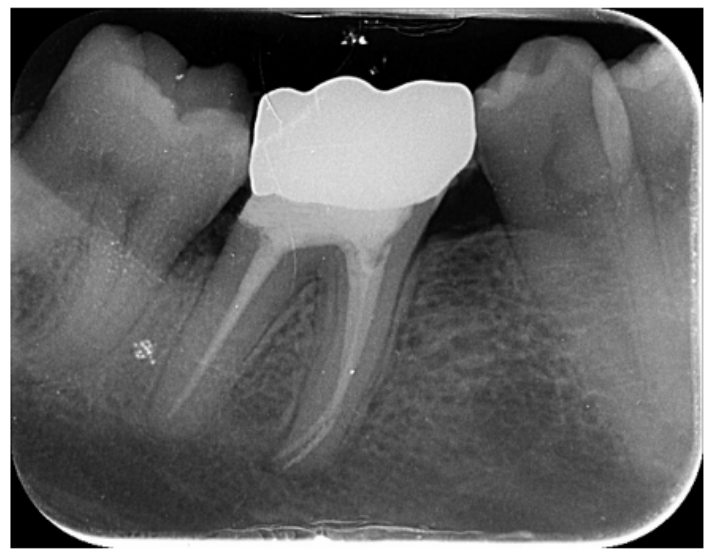

Figure 5: One year follow-up of the case after restoring the tooth with fix prosthesis.

pressive stresses. Torsion and failure occur when the tip of the file binds in the canal whilst the instrument continues to rotate [10,12-14]. Generally, coronal fractures of instruments are more likely to be due to cyclic fatigue whilst apical fracture are more often due to torsional stresses [15]. Stainless steel and hand instrument will generally separate due to torsional failure but engine-driven NiTi instruments will usually fail due to combination of torsional and cyclic fatigue [15]. 


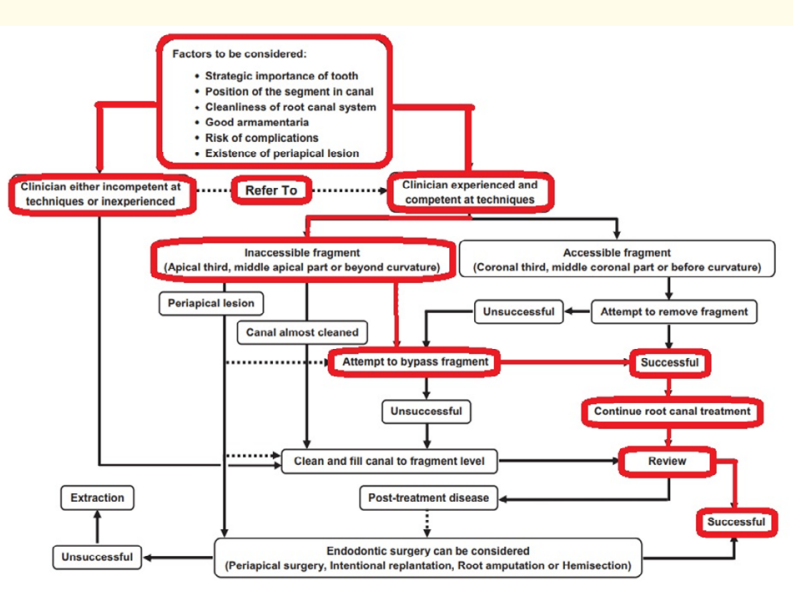

Figure 6: Decision-making flowchart of management of intercanal separated instrument by Madarati., et al. 2013. The highlighted in red is the approach followed in the present case.

The incidence of instrument fracture has been reported to be between 0.7 and 7.4\% [9,16-20], it can be considered that root canal anatomy is a critical factor contributing to instrument fracture, and the multi-planner curvatures frequently observed in mesial roots of molar teeth appear to be predisposed to this. Based on the current literature, mandibular molars are commonly affected teeth. Restricted access may act as a further complicating factor [15]. When separated instrument occurs, the treating clinician may often be overwhelmed with how to appropriately manage this patient. Clear an informative communication is essential to minimize the risk of a complaint.

The main goal of management of separated instrument is not only retrieving the fragment but also preserving the integrity of the tooth. With the associated complications, bypassing a fragment located deep in the root canal or beyond the root curvature, if possible, maybe the appropriate treatment option [10]. A separated instrument itself is not the main cause of treatment failure but rather an indirect one, because it prevents adequate cleaning, shaping coma and feeling of the root canal [21].

In this case our main goal was either remove the separated instrument or bypass the separated instrument to reach to the apical area which it could be irrigated and cleaned thoroughly.
Successful removal of an instrument is largely dedicated by the ability to visualize it this can normally only be achieved with a surgical operating microscope or high magnification loupes with appropriate lightning [22], in which it was not available. Removing the separated instrument was considered and begin by using the ultrasonic tip, but due to no visual contact the risk of continuing with this method was riskier than retrieving the separated instrument, because there was a high chance of excessive remove of dentine which may led to perforation or weakening of the root. A retained fractured instrument may have less impact on treatment outcome than the perforation which could occur as a result of attempting removal of the file $[23,24]$. Therefore, care and good judgment should be used while treating tooth and the decision was shifted toward bypassing the separated instrument. The sequencing of the filing from smaller to larger was to penetrate gradually, which smaller sizes helped to penetrate, and the larger size helped to enlarge the canal. this was carried out under $3.5 \mathrm{x}$ loups and taking radiographs check to avoid any other complications. Bypassing separated instruments has been categorized as a successful approach [14,16,25-27]. The flowchart, which was recommended by Madarati., et al. 2013, how to manage intercanal separated instrument.

\section{Conclusion}

Handling separated instrument in root canal system varies due to different factors which includes location of separated instrument in the root canal system, the anatomy of the canals, skills of the clinician, different armamentaria which is available, and the presence or absence of preapical lesion.

Removing separated instrument is not always possible, especially if excellent magnification and light is not available. In this case, bypassing the separated instrument proved to be a better approach compared to retrieving the separated instrument. It can concluded that bypassing the separated fragment may be a novel and better approach in terms of preserving the tooth structure and dentine preservation within the canals leading to longer survival rate.

\section{Bibliography}

1. L S. The dependence of the results of pulp therapy on certain factors: an analytic study based on radiographic and clinical 
follow-up examination". Acta Odontologica Scandinavica 14 (1956): 1-175.

2. Torabinejad M MN. "Endodontics Principles and Practice". $4^{\text {th }}$ edition. St Louis: Elsevier Health Sciences (2009).

3. Vaudt J., et al. "Ex vivo study on root canal instrumentation of two rotary nickel-titanium systems in comparison to stainless steel hand instruments". International Endodontic Journal 42.1 (2009): 22-33.

4. Bonaccorso A., et al. "Shaping ability of four nickel-titanium rotary instruments in simulated S-shaped canals". Journal of Endodontics 35.6 (2009): 883-886.

5. Lopes HP., et al. "Influence of rotational speed on the cyclic fatigue of rotary nickel-titanium endodontic instruments". Journal of Endodontics 35.7 (2009): 1013-1016.

6. Cheung GS and Liu CS. "A retrospective study of endodontic treatment outcome between nickel-titanium rotary and stainless steel hand filing techniques". Journal of Endodontics 35.7 (2009): 938-943.

7. Jafarzadeh $\mathrm{H}$ and Abbott PV. "Ledge formation: review of a great challenge in endodontics". Journal of Endodontics 33.10 (2007): 1155-1162.

8. Ankrum MT., et al. "K3 Endo, ProTaper, and ProFile systems: breakage and distortion in severely curved roots of molars". Journal of Endodontics 30.4 (2004): 234-237.

9. $\mathrm{Wu}$ J., et al. "Instrument separation analysis of multi-used ProTaper Universal rotary system during root canal therapy". Journal of Endodontics 37.6 (2011): 758-763.

10. Madarati AA., et al. "Management of intracanal separated instruments". Journal of Endodontics 39.5 (2013): 569-581.

11. Glickman GN. "AAE Consensus Conference on Diagnostic Terminology: background and perspectives". Journal of Endodontics 35.12 (2009): 1619-1620.

12. Fu M., et al. "Removal of broken files from root canals by using ultrasonic techniques combined with dental microscope: a retrospective analysis of treatment outcome". Journal of Endodontics 37.5 (2011): 619-622.
13. Gambarini G. "Cyclic fatigue of ProFile rotary instruments after prolonged clinical use". International Endodontic Journal 34.5 (2001): 386-389.

14. Al-Fouzan KS. "Incidence of rotary ProFile instrument fracture and the potential for bypassing in vivo". International Endodontic Journal 36.12 (2003): 864-867.

15. Bhuva B and Ikram 0. "Complications in Endodontics". Primary Dental Journal 9.4 (2020): 52-58.

16. Parashos P and Messer HH. "Rotary NiTi instrument fracture and its consequences". Journal of Endodontics 32.11 (2006): 1031-1043.

17. Iqbal MK., et al. "A retrospective clinical study of incidence of root canal instrument separation in an endodontics graduate program: a PennEndo database study". Journal of Endodontics 32.11 (2006): 1048-1052.

18. Spili P., et al. "The impact of instrument fracture on outcome of endodontic treatment". Journal of Endodontics 31.12 (2005): 845-850.

19. Wolcott S., et al. "Separation incidence of protaper rotary instruments: a large cohort clinical evaluation". Journal of Endodontics 32.12 (2006): 1139-1141.

20. Fishelberg G and Pawluk JW. "Nickel-titanium rotary-file canal preparation and intracanal file separation". Compendium of Continuing Education in Dentistry 25.1 (2004): 17-18.

21. Saji S GP., et al. "Management of Instrument Separation: A Case Series". Conservative Dentistry and Endodontic Journal 4.2 (2019): 39-43.

22. Low JF., et al. "Magnification in endodontics: A review of its application and acceptance among dental practitioners". European Journal of Dentistry 12.4 (2018): 610-616.

23. Ng YL., et al. "A prospective study of the factors affecting outcomes of nonsurgical root canal treatment: part 1: periapical health". International Endodontic Journal 44.7 (2011): 583609.

24. Ng YL., et al. "A prospective study of the factors affecting outcomes of non-surgical root canal treatment: part 2: tooth survival". International Endodontic Journal 44.7 (2011): 610-625. 
25. Hülsmann M and Schinkel I. "Influence of several factors on the success or failure of removal of fractured instruments from the root canal". Endodontics and Dental Traumatology 15.6 (1999): 252-258.

26. Shen Y., et al. "Factors associated with the removal of fractured NiTi instruments from root canal systems". Oral Surgery, Oral Medicine, Oral Pathology, Oral Radiology, and Endodontics 98.5 (2004): 605-610.

27. Nevares G., et al. "Success rates for removing or bypassing fractured instruments: a prospective clinical study". Journal of Endodontics 38.4 (2012): 442-444.

Volume 5 Issue 9 September 2021

(C) All rights are reserved by Gurdeep Singh., et al. 